\title{
THE EFFECTIVENESS OF A TOEIC PREPARATION COURSE ON NON- ENGLISH MAJORED STUDENTS' TOEIC SCORES AT A UNIVERSITY IN VIETNAM
}

\author{
NGA THI TUYET PHAN, HA TRONG QUANG, TRUONG TRAN MINH NHAT \\ Industrial University of Ho Chi Minh City, \\ ngaphan@iuh.edu.vn
}

\begin{abstract}
This study aims to examine whether non-English majored students' TOEIC scores are improved after participating in a TOEIC preparation course. Another purpose is to understand possible reasons affecting the scores. To accomplish the two purposes of the study, students' TOEIC scores before and after a TOEIC preparation course in a natural classroom setting were analyzed using Paired-samples t-test. Focus group discussions were used to understand reasons that led to changes in scores. Findings suggest that students' TOEIC scores were not improved when they finished the course. The study students' perceptions of their effort, background knowledge, motivation, limited instructional time and a change in selected answer choices appeared to negatively affect their achievements.
\end{abstract}

Keywords: TOEIC scores, non-English majored students, effectiveness, TOEIC preparation courses

\section{INTRODUCTION}

English today is the international language. Over 85 percent of international organizations make some official use of English. This is true in Asia and the Pacific where about 90 percent of international bodies carry on their proceedings only in English [1]. English is the key in enabling countries to discuss and negotiate political, social, educational, and economic aspects. The widespread use of English makes it imperative for any country wishing to access the global community for economic development. Put differently, the language plays a key role in the economic development of a country.

The close relationship between English and job-seeking has made the need to improve graduates' English communicative competence urgent. A TOEIC (Test of English for International Communication) certificate has recently become a graduation requirement in many universities in Vietnam [2]. As a matter of fact, many TOEIC preparation courses are offered throughout the country from English learning centers to universities to help students achieve desired scores. Since there has not been much research on the effectiveness of these courses, it is questionable whether the offered learning courses prepare students fully for TOEIC tests, whether their students are confident in sitting the tests and whether their scores are improved after the courses.

The main purpose of this study is to examine whether non-English majored students' TOEIC scores are improved after participating in a TOEIC preparation course. Another purpose is to understand possible reasons affecting the scores. To accomplish the two purposes of the study, students' TOEIC scores before and after a TOEIC preparation course in a natural classroom setting were analyzed using Paired-samples t-test. In addition, focus group discussions were used to understand reasons that led to changes in scores. By investigating the effectiveness of a TOEIC preparation course, the study will contribute to the review of TOEIC teaching materials and methods at the local university, which may provide local language teachers with insights to improve the quality of TOEIC courses as well as its organization. This will ultimately contribute to students' successful language performance. In the long term, graduates from Vietnamese institutions may have the English language skills to better serve the labour market needs of Vietnam and the region. In this fashion, the study will benefit foreign language acquisition for pedagogical purposes. The study addressed the following questions:

1. Are students' TOEIC scores improved after the TOEIC preparation course?

2. What factors affect the scores? 


\section{LITERATURE REVIEW}

\subsection{The TOEIC Reading and Listening Test:}

TOEIC is a standardized test that is used as a tool to measure people's English skills to understand, use and communicate in English. Many businesses, corporations, government agencies and educational institutions throughout the world have used the TOEIC test to judge if a person is qualified to become one of their workers, to remain one of their workers, or to be promoted. Educational Testing Service (ETS) developed the TOEIC test and is the official organization that administers the test. According to ETS, the tests are marked by rigorously trained ETS graders who follow strict rules to guarantee the test's consistency. This ensures scores that are fair, reliable and consistent yearly.

The TOEIC test is relied on throughout the world for over 35 years now [3]. The TOEIC Listening and Reading Test is a 2 hour multiple-choice test consisting of 200 questions. Test candidates must have strong vocabulary and grammar skills as well as being able to read and listen to English fluently. They are expected to quickly understand and respond to the workplace situations they are presented with in the test. The test is claimed to be an accurate reflection of what test candidates will encounter in the international working environment. Test takers have 45 minutes to complete 100 multiple choice questions for Listening. There are 4 different sections, each with a different kind of stimulus. Reading is also 100 multiple choice questions which should be completed in 75 minutes. Reading consists of 3 different sections, each with a different kind of stimulus. After the test, each candidate receives independent scores for Listening and Reading comprehension on a scale from 5 to 495 points. The total score adds up to a scale from 10 to 990 points [3].

Preparation for the TOEIC test is important. It is advised that students should practice their English skills daily by immersing themselves in the target language frequently and in many ways. Currently, there exist a lot of learning materials on the Internet and from bookstores. Regarding preparation time, research shows different amount of preparation time for different kinds of learners. For example, 200-level learners might expect a 100-point gain after just 100 hours of instruction, but 500-level learners might need 250 or 300 hours to gain 100 points. Researchers also suggest that intensive study, e.g., classes meeting every day for two or three hours, is likely to be more beneficial than classes that meet only once a week for an hour or two. If students are required to take the test before there is significant improvement, it is likely that they will be disappointed and discouraged when their scores are not as high as they expect [4].

\subsection{The TOEIC course:}

Students at the university where the study was conducted are offered two consecutive TOEIC preparation courses in the second and third semester. Each course lasts 45 periods in approximately 15 weeks. Students meet once a week for two hours and ten minutes. The TOEIC scores before and at the end of the offered courses are institutional ones administered by Faculty of Foreign Languages. The textbook used for the course is TNT TOEIC: Basic course. The course features (a) review of basic grammar, (b) a review of listening and reading skills, c) reading and listening practice and (d) exam skills. The target TOEIC scores at the end of the first and second course are 250 and 350 respectively. Students are encouraged to obtain 450 by graduation as the university requirement. According to [3], students achieving under 250 points are basic beginners and able to satisfy immediate survival needs. Those getting from 255 to 400 are at elementary level and have functional but limited proficiency. They are able to maintain very simple face-to-face conversations on familiar topics. Immediate level learners earning from 405 to 600 can initiate and maintain predictable face-to-face conversations and satisfy limited social demands.

All sophomores at the university before joining the TOEIC courses learnt basic grammar, reading and listening lessons in junior and senior high school. At primary, junior and senior high school levels in Vietnam, the testing of English is mainly confined to reading and writing skills due to the lack of resources and ill-defining testing criteria in the curricula [5], [6]. Consequently, high school leavers will probably have problems in communication skills in general and in learning TOEIC Listening skills in particular when they are at university level. 


\subsection{Previous studies on the effectiveness of TOEIC preparation courses}

Despite the increasing importance of TOEIC certificates to students' job-seeking and the growing number of TOEIC preparation courses, there has been very little research into the question of whether preparation courses can help improve TOEIC scores. Among the very few studies which have investigated this issue, researchers have reached different results.

Some researchers (e.g. [7], [8], [9] [10], [11]) suggest that TOEIC courses had a significant influence on improving students' TOEIC scores. For example, [7] conducted a quantitative study to investigate the effects of the TOEIC course at a junior college in Tokyo. The TOEIC scores of 60 first-year students were analyzed by one-way ANOVA and $t$-tests. The relationship between the vocabulary test and TOEIC scores was estimated using Pearson product-moment correlations. The results showed that the TOEIC course was effective in improving students' TOEIC scores. In 2014 and 2015, TOEIC scores increased by approximately 100 points in nine months. In 2016, scores rose by around 90 points in only three months. Similarly, [12] and [8] found out that the intensive TOEIC preparation program helped improve students' overall scores significantly. However, students' listening comprehension scores did not increase significantly after the preparation courses. Articulation, textbook and facility were claimed to contribute to the successful results.

Another group of researchers argue that TOEIC preparation courses do nothing to improve students' scores. For example, [13] compared the two sets of students, that is, English majors and non-English majors, in their own study investigating the effects of TOEIC. The second set of students was further divided into three treatment groups, one studied with TOEIC preparation materials, one studied business English and one had a four-skills general English class. With the exception of one group, there was no difference due to what materials the students studied. The non-major TOEIC preparation group did show significant gains on their reading scores. However, the researchers believed that the non-majors' lower initial scores may have been a contributing factor. Therefore, they cautioned against applying the findings to other teaching situations. Recently, [14] conducted a study with 60 students in a technical college in northern Taiwan to understand if the TOEIC preparation courses helped technical college students in the TOEIC exam. No significant improvement on the TOEIC test scores after students' engaging in this preparation program was detected. The researcher listed several reasons for the disappointing result of the course, including students' low learning motivation, limited vocabulary, poor grammar skills and slow reading speed.

The literature above has demonstrated contradictory results regarding the effectiveness of TOEIC courses. In addition, in Vietnam, no studies have investigated the issue so far. Therefore, it is necessary to conduct a similar research on a TOEIC preparation course at a Vietnamese university.

\section{METHODS}

\subsection{Participants:}

Participants included 94 Vietnamese second-year students at a technical university in Vietnam. The participants majored in Accounting, Electronic Engineering, Machinery Engineering, Food Technology, and Chemical Engineering.

\subsection{Material and Procedure:}

Students' TOEIC scores before and after a TOEIC preparation course in a natural classroom setting were compared by using the Statistical Package for Social Sciences (SPSS) version 20.0. Focus group discussions were used to understand reasons that led to changes in scores.

The test: Students were invited to take a pre-test (TOEIC mock test) and a post-test (TOEIC mock test) before and after the fifteen-week program. It is important to note that the TOEIC mock tests here were not the same as the institutional ones administered by Faculty of Foreign Languages. The mock tests were conducted one week before the institutional tests and were taken from IIG's previous test booklets. The test procedures and regulations applied to the mock tests. Therefore, it is likely that students' scores of the mock test reflect their scores in the institutional ones. 
According to [3], the TOEIC Listening and Reading test uses the KR-20 reliability index which assesses the extent to which all items measure the same construct. ETS claims that the reliability of the TOEIC Listening and Reading section scores across all forms from their samples has been approximately 0.90 and up. Regarding validity, ETS states that the TOEIC Listening and Reading test includes a variety of important English language tests.

Focus group discussions: This research instrument is generally regarded as facilitating participation and interpersonal communication and to encourage a supportive environment [15], which aligns broadly with certain Vietnamese cultural values. Because participating students in the study had never participated in any research, the stressful feeling probably produced by their first-time participation in research was hopefully lessened by peers' presence [16]. Participating students were invited to different focus group discussions conducted immediately after the second TOEIC mock test. In the discussions, students expressed their perceptions of factors relating to the TOEIC preparation class and English learning. Each focus group discussion lasted approximately 60 minutes and it was audio recorded. There were 9 focus group discussions in total.

\subsection{Data analysis:}

To analyse qualitative data, the first author used an inductive coding process [17] and thematic analysis [18]. The quantitative data analysis was made by using the Statistical Package for Social Sciences (SPSS) version 20.0. For the analysis of the effectiveness of the TOEIC classes, differences in TOEIC scores were analyzed using a Paired-samples t-test.

\section{RESULTS}

\subsection{Comparisons of Pre-test and Post-test: Quantitative data}

Results from a Paired-samples t-test are given in the tables. The mean rating for scores before the course was 280.21 and after the course was 254.74 . The average TOEIC total scores decreased by 25.468 points. The differences were statistically significant.

Table 1: Students' TOEIC scores

Paired Samples Statistics

\begin{tabular}{|l|l|l|l|l|l|}
\hline \multicolumn{2}{|c}{} & Mean & N & Std. Deviation & Std. Error Mean \\
\hline \multirow{2}{*}{ Pair 1 } & score 2 & 280.21 & 94 & 19.810 & 2.043 \\
\cline { 2 - 7 } & score 3 & 254.74 & 94 & 44.328 & 4.572 \\
\hline
\end{tabular}

Paired Samples Correlations

\begin{tabular}{|l|l|l|l|l|}
\hline \multicolumn{2}{|l|}{} & N & Correlation & Sig. \\
\hline Pair 1 & score 2 \& score 3 & 94 & .296 & .004 \\
\hline
\end{tabular}

Paired Samples Test

\begin{tabular}{|l|l|l|l|l|l|}
\hline \multicolumn{2}{|l|}{} & Paired Differences & \multicolumn{2}{|l|}{} \\
\cline { 3 - 6 } & & Mean & Std. Deviation & Std. Error Mean & $\begin{array}{l}\text { 95\% Confidence } \\
\text { Interval of the } \\
\text { Difference }\end{array}$ \\
\hline Pair 1 & score 2 - score 3 & 25.468 & 42.872 & 4.422 & Lower \\
\hline
\end{tabular}

Paired Samples Test

\begin{tabular}{|l|l|l|l|l|}
\hline \multicolumn{2}{|l|}{} & $\begin{array}{l}\text { Paired Differences } \\
95 \% \text { Confidence } \\
\text { Interval of the } \\
\text { Difference }\end{array}$ & Sig. (2-tailed) \\
\hline Upper & 34.249 & 5.760 & 93 & .000 \\
\hline Pair 1 & score 2 - score 3 & & & \\
\hline
\end{tabular}




\subsection{Factors affecting the scores: Qualitative data}

The rationale behind the changes in students' scores was revealed in the focus group discussions conducted with students in three classes. Findings suggest that the students' perceptions of their effort, background knowledge, motivation, limited instructional time and a change in selected answer choices affected their TOEIC scores.

\subsubsection{Effort}

Most students confessed that they did not put much effort as required to practice English at home. Few of them invested more than 1 hour daily listening to English or doing homework. None of the students explored external learning materials on the Internet although they reported their teachers' emphasis of the importance of self-learning many times during class hours. Some students agreed that they were "aware of the importance of practicing English at home"; however, they were "not hardworking enough" and "easy to give up when confronting difficult exercises". The limited amount of effort putting into learning English outside the classroom is likely to link to their limited background knowledge and lack of motivation which are presented in turn below.

\subsubsection{Background knowledge}

Many students stated that their lack of listening skills at junior and senior high school prevented them from doing well in a TOEIC test. A large number of students reported that although there were listening lessons in high school textbooks but they "got few opportunities to be exposed to native speakers from the CDs". Instead, it was "the teachers" who read aloud the conversation and students did the listening exercises. Therefore, when it came to do a TOEIC listening task, students confronted with "too many new words and complicated ideas which were said too quickly and in strange voices". In addition, all of the students reported that they had limited knowledge of TOEIC test skills and TOEIC learning strategies. Students did not find acquired learning strategies at high school helpful to expand their vocabulary size because TOEIC vocabulary covers a range of topics which might require different strategies.

\subsubsection{Motivation}

It is not surprised when almost all of the participating students made clear that they were not motivated to learn new words and structures or self-study as required. They lost their willingness and interest towards the lessons because "doing exercises all the time [was] tiring and boring". The students stated that teachers spent all class hours teaching new structures and providing corrective feedback which seemed not to be always helpful to improve their competence. Class time was reported to be "really stressful", "boring" and students felt unmotivated to learn.

\subsubsection{Limited instructional time}

Most students in the study were dissatisfied with current amount of class time and stated that they received fewer contact hours than they had expected. On average, students have 3 hours of learning time and 6 hours of independent study weekly. The students stated that they needed more intellectual support from the teachers to develop basic skills and knowledge. According to the students, extended learning time would give teachers more time to "lecture", "cover things in the textbook", "build rapport with students", "explain things" and "check homework" in the classroom. Besides, participating students reported that they themselves also needed more time in class to do exercises and complete their work under the direct supervision of the teachers.

\subsubsection{A change in selected answer choices}

Some students stated that the way they selected correct answer choices largely changed near the end of the course. During the first test, these students chose the answers randomly although they were not sure whether the answers were correct. "I just chose option A for the first five questions, B for the next ones and so on". However, during the second test near the end of the course, the students felt they could not do the same way. "I had to think about why I should choose this option, not the other but it took me a lot of time to think. The test was too long and I ran out of time!" "I already got some knowledge which made 
me think about different options". The changed selection contributed to lower scores in reality; however, this indicated that students already gained some knowledge and need coaching regarding learning strategies as discussed in the discussion section below.

\section{DISCUSSION}

Findings from the study indicated that students' TOEIC scores were not improved when they finished the course. Instead, their scores decreased by 25.468 points. The mean score immediately before the institutional test was 254.74 which was lower than the criterion of passing of 350 .This finding this similar to what [14] found out as discussed earlier in the literature review section. It appears that there exist some factors which resulted in the lack of improvement in students' scores.

Firstly, demotivation is one factor that hinders students from putting more effort into learning. Most students in the study stated that the class was not fun at all and really stressful since teachers focused on teaching exam techniques and giving corrective feedback. The negative washback effects of TOEIC test have been discussed much in the literature [19] as [20] claimed that a test "cannot determine how teachers teach, however much it might influence what they teach" (p. 127, emphasis in original). In order to increase the average TOEIC scores for technical university students, it is essential to take motivation factor into consideration. No matter how good the teaching method is or how effective their teachers are, students' scores will not increase if they do not study. Therefore, it is rather important for the teachers to find ways to encourage students to study hard during and after class [14]. References [19] and [21] provided some suggestions that successful exam teachers can apply in their classroom in order to engage EFL students in TOEIC preparation classes. For example, teachers should create a balance between the teaching-centered approach and the student-centered approach, e.g. including pair work, group activities and games in teaching plans.

Findings also suggest that most students did not have clear understanding of how to develop good study habits and learning strategies of TOEIC, which negatively affected their scores. This finding is not surprising since students' English proficiency varies between students from rural areas and urban areas [22]. In addition, it is likely that the language knowledge required for a TOEIC test was different from language knowledge gained at high school [14]. Reference [23] emphasized the need to encourage students to develop good study habits and build exam skills to achieve the best results. Teachers can help students familiarize themselves with the test and test-item types in the classroom. However, since class length and class time are limited, it would be ideal if the local university offers soft-skills courses outside timetabled sessions coaching sophomores to develop the organizational skills and discipline required for standardized tests. When coaching students to build up their study habits and TOEIC learning strategies, student motivation should be taken into account as discussed above.

In the present study, limited class time seems to be one problem that caused students' low scores. The lower-level students expressed their hope for extended class hours in order to get more intellectual support from the teachers in class and to develop basic skills and knowledge. However, the global trend now is a focus on improving existing learning time rather than using an extending time model. It is clear that the amount of instructional time is not so important as how that time is spent [24]. With a decreased number of class periods per day, teachers should think of opportunities to implement creative teaching strategies to meet the needs of students and have more one-to-one time for interactions with students in class. An example of implement creative teaching strategies is to flip the classroom to optimize instructional time [25]. Flipped classrooms are known as to create a community learning inside and outside the classroom without using too much class learning time since students practice lower-order skills such as information gathering and memorization at home prior to class.

This study also has several suggestions for future course design. First, the priority should be the teaching in listening since most students expressed concerns on their lack of listening skills and strategies. It is evident that at high school, listening skills were not emphasized and students lack opportunities to practice the skills beyond the classroom. Second, it is important to help students acquire more TOEIC vocabulary and complex structures. Knowing more English words and structures related to the working environment will help students score higher in the TOEIC exams and improve their reading and listening speed accordingly. In order to help students develop the skills that they will demonstrate on the test, [26] 
listed a range of activities that can be practical for lower-level students. It is likely that students will be able to finish the reading questions within the time limit and then score higher in the reading comprehension section. Their listening skills will possibly be improved if they are exposed to different accents and a range of listening tasks systematically.

\section{CONCLUSION}

The purpose of this study is to understand whether sophomores' TOEIC scores were improved after they participated in a TOEIC preparation course and possible reasons affected the results. Findings indicated that students achieved lowered scores due to limited effort, lack of background knowledge, demotivation, limited class time and a change in selected answer choices. This research has the potential to inform TOEIC preparation courses in Vietnam and in similar settings.

Limitations: The tests used in this study were the mock TOEIC tests which were publicized by ETS. It is possible that some students had even done the same mock tests before so that the scores were not accurate. In order to have a more accurate comparison, the official TOEIC test should be used in future studies. In addition, there were no control groups being manipulated in the present study. Therefore, generalizing the results to a wider EFL context, e.g. the whole TOEIC learners in Vietnam as a population, should be careful. To further test the effectiveness of TOEIC preparation courses, an experimental study encompasses both the control and the experiment group is called for. Future studies should also include teachers' voice in understanding the reasons affecting students' scores.

\section{REFERENCES}

[1] McKay, S. L., Teaching English as an international language, 2002, Oxford: Oxford University Press.

[2] Doan, C., Foreign languages certificates: Hard debts to pay (Chúng chỉ ngoại ngũu: Món nợ khó trả! ), 2017, April 4, Retrieved from https://nld.com.vn/giao-duc-khoa-hoc/chung-chi-ngoai-ngu-mon-no-kho-tra20170409213836012.htm

[3]ETS., Examinee Handbook: Listening and Reading, 2015,. Retrieved from https://www.ets.org/s/toeic/pdf/listening-reading-examinee-handbook.pdf

[4] Childs, M., "What you can expect from TOEIC preparation", The Daily Yomiuri, (2002) Oct. 18: 18. Retrieved on October 5, 2010 from https://db.yomiuri.co.jp/dpscripts/DpDetail.dll?Detail

[5] Tran, T. X., National foreign language 2020 Project to standadize ELT in Vietnam: a dream too big? Paper presented at the 2012 VUS annual conference: ELT practices and standardization: Options and Perspectives, 2012, July, Ho Chi Minh city, Vietnam.

[6] Truong, H. V. H., Assessment on new English textbooks at secondary level. Paper presented at the Educational Research Institute's Conference: The role of assessment in education innovation in Vietnam, 2004, May, Ho Chi Minh city, Ho Chi Minh city University of Pedagogy.

[7] Harada, S., "Effects of the TOEIC course on students' TOEIC scores", The Bulletin of St. Margaret's, 48, (2016), 1-17.

[8] Lai, Yi-hsiu., “A study on the effectiveness of college English-featured courses on TOEIC”. 高雄師大學報, 25, (2008), 71-91.

[9] Siriboon, N., Toeic preparation course at Toyota motor Thailand: The impact of English language development on employees (Master's Thesis), 2008, Thammasat University, Bangok, Thailand.

[10] Taguchi, K., “An exploratory study on correlations among vocabulary size, vocabulary learning strategy use,TOEIC scores and self-efficacy”. The Economic Review of Toyo University, 41(2015): 1, 55-67. 
[11] Wu, Hsing-ling., "Implementation of an elite sophomore English class at a university in Taiwan", Hsiuping Journal of Humanities and Social Sciences, 21, (2013), 21-30

[12] Kang, C. C., "Pedagogical Implications of Score Distribution Pattern and Learner Satisfaction in an Intensive TOEIC Course". English Language Teaching, 7 (2014): 11, pp. 64-78.

[13] Robb, T. N., \& Ercanbrack, J., "A study of the effect of direct test preparation on the TOEIC scores of Japanese university students", TESL-EJ, 3: (2004): 4, 1-22.

[14] Hung, C-H., "Effectiveness of TOEIC Preparation Courses for Technical College Students". Journal of Oriental Institute of Technology, 37 (2017), pp. $31-40$.

[15] Thomas, A., "Focus groups in qualitative research: culturally sensitive methodology for the Arabian Gulf?", International Journal of Research \& Method in Education, 31 (2008): 1, 77-88. 10.1080/17437270801919941

[16] Marshall, C., \& Rossman, G. B., Designing qualitative research (5th ed.), 2011, Thousand Oaks, CA: Sage.

[17] Creswell, J. W., Educational research: planning, conducting, and evaluating quantitative and qualitative research (4th ed.), 2012, Boston: Pearson.

[18] Braun, V., \& Clarke, V., "Using thematic analysis in psychology", Qualitative Research in Psychology, 3 (2006): 2, 77-101. 10.1191/1478088706qp063oa

[19] Apichatrojanakul, P., "The Washback Effects of the TOEIC Examination on the Teachers and Students of a Thai Business School”, Language Testing in Asia, 1 (2011): 1, pp. 62-75.

[20] Alderson, J. C., \& Wall, D., “Does Washback Exist?” Applied Linguistics, 14, (1993), 115-129. http://dx.doi.org/10.1093/applin/14.2.115.

[21] Sarich, E., "A guide to planning and executing a TOEIC preparation course", The Language Teacher, 38 (2017): 1, pp. 17-21.

[22] Phan, N. T. T., Can I teach these students? A case study of Vietnamese teachers' self-efficacy in relation to EFL (Doctoral dissertation), 2015, The University of Waikato, Hamilton. Retrieved from http://researchcommons.waikato.ac.nz/handle/10289/9433

[23] Burgess, S. \& Head, K., How to teach for exams, 2005, England: Pearson, Longman.

[24] Joyner, S. \& Molina, C., Class time and student learning, January, 2012, Retrieved July, 25, 2018 from http://www.sedl.org/txcc/resources/briefs/number6/

[25] Bergmann, J., \& Sams, A., Flip your classroom: Reach every student in every class every day, 2012, Washington, DC: ISTE; and Alexandria, VA: ASCD.

[26] Brown, H., Learner perceptions of TOEIC test results and language skill improvements: “I don't want to study English, I want to study TOEIC”. In K. Bradford-Watts, C. Ikeguchi, \& M. Swanson (Eds.) JALT2005 Conference Proceedings, 2006, Tokyo: JALT.

Received on February $1^{\text {st }}$, 2019

Accepted on March 25 $5^{\text {th }}, 2019$ 